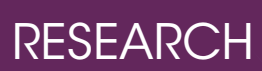


Research is often used as a method for generating new professional knowledge, building upon existing knowledge and closing perceived knowledge gaps. Approaches to research are informed and underpinned by different knowledge constructs. ${ }^{2}$

Research is best used to improve patient care and treatment outcomes to inform evidence based dentistry. The Evidence-Based Medicine Working Group ${ }^{3}$ introduced the term 'evidence based dentistry' to the dental profession.

Richards and Clarkson ${ }^{4}$ believe that evidence based dental practice is a structured approach for clinical decision making, assists the practitioner in finding, distilling, and applying the best evidence in clinical practice, and manages the problem of information overload and uncertainty. The best method of finding research to use to improve patient treatment and care is to undertake a literature review.

\section{What is a literature review?}

Undertaking a literature search can be a complex and time consuming process; however, there are a number of tools such as the LoBiondo-Wood and $\mathrm{Haber}^{5}$ (Fig. 2) steps and strategies for searching literature to use as a framework for conducting a literature review search.

*An international research mission

Dr Barry Quinn and Mr Richard

Johnson were elected onto the

Executive Team of the International

Association of Dental Research (IADR)

Education Research Group at the

General Meeting held in Iguaçu Falls

in Brazil in June this year. Barry will

perform the role of Councillor and

Richard the role of Secretary for a term of three years.

The IADR, headquartered in

Alexandria in the USA, is a non-profit

organisation with nearly 12,000

members worldwide. Its mission is:

1. To advance research and increase knowledge for the improvement of oral health worldwide

2. To support and represent the oral health research community

3. To facilitate the communication and application of research findings.

The IADR Education Research Group is a dynamic group of educators, scientists and clinicians whose scope of research targets all aspects of dental education: learning, teaching, technology and innovation.

\section{'Research is}

often used as

a method for generating new professional

\section{knowledge...'}

In the field of research a literature review is widely recognised as a scholarly activity, despite there being no universally held belief of what constitutes a body of literature. Therefore each reviewer must select their own inclusion/ exclusion criteria.

Online databases can be used to search for relevant literature in scientific nursing and dental journals with a limited hard copy article and research paper hand search undertaken in libraries. As Holmes ${ }^{6}$ states books are of little value in literature searches as the information contained within them is generally outdated by time of publication.

\section{Analysis of research studies}

Once a literature review has been undertaken the reviewer must critique the studies found. Cowan ${ }^{2}$ states that the ability of professional practitioners to analyse and synthesise the research evidence that facilitates practice, allows them to critically evaluate the potential of a variety of research methods in answering health and social care research questions.

Parahoo ${ }^{7}$ believes the task of critiquing is a challenge and can only be acquired through practice. It requires extensive detailed reading and careful checking of the conclusion against the evidence provided.

Cowan ${ }^{2}$ in his excellent book Research issues in health and social care that demystifies research, states that a good critical appraisal should consider the following general points:

- Have issues been considered?

- What assumptions has the author made about the readers?

- What sort of article is it? Is it research or a review?

- What method was used and was it appropriate?

- Has the author achieved their objective, if stated, or what is it that the author meant to achieve?
- Are the conclusions/views of the author supported by the critical appraisal?

- Is the author attempting to stimulate debate - if so is it appropriate?

- Is there sufficient reference to available literature?

- Has the literature been well integrated into the text?

- Is the text well justified in using other work or does it read as the author's opinion?

- Are all relevant concepts and variables included in the review?

- Is there evidence that the work is unbiased?

- Was the work original? If not did it still constitute an important addition to knowledge?

- Was the study design feasible/ sensible/appropriate?

- What outcomes were chosen and how were they measured?

- Who was in the study; how were they selected and recruited?

- Who was included, who was excluded and why?

- Was the study undertaken in a realistic (true to life setting) or was it in a highly controlled environment?

Once the reviewer is happy with the literature found it can be used in practice to improve patient care and treatment. This often takes the form of clinical audit.

\section{Clinical audit and research}

Clinical audit is defined by the National Institute for Health and Clinical Excellence (NICE) as 'a quality improvement process that seeks to improve patient care and outcomes through systematic review of care against explicit criteria and the implementation of change.8 The White Paper Working for patients ${ }^{9}$ introduced the use of clinical audit as required practice for all healthcare practitioners. Audit is often the healthcare practitioner's first exposure to partaking in a study.

However, there is a difference between clinical audit and research, with research being about creating new knowledge, such as developing new treatments or finding out which treatments are better than others. It determines what best practice is.

Clinical audit and research are similar (Fig. 3 ) as they involve answering a specific question relating to the quality of care or service; both can be carried out either prospectively or retrospectively and involve careful sampling, questionnaire design and analysis of findings. However, there are some major differences:

- Research creates new knowledge and best practice; clinical audit tells us if we are following best practice 
- Research is based on a hypothesis; clinical audit measures against standards

- Research can involve patients trying an untested treatment method; clinical audit never involves patients trying new treatment methods

- Research may involve a degree of experimentation on patients; clinical audit never involves experimentation

- Research may involve allocating patients to different treatment groups; clinical audit includes all patient groups

- Research may be based on a scientifically valid sample size; clinical audit sample sizes don't need to be scientifically valid

- Research findings can have a wide reaching influence on clinical practice; clinical audit has a local influence on clinical practice but can be shared widely

- Research involving staff, patients and data collection requires ethics committee approval; clinical audit rarely requires ethics approval.

\section{'Research}

\section{findings can}

\section{have a wide}

reaching

\section{influence on}

\section{clinical practice;} clinical audit has

\section{a local influence} on clinical practice.'

\section{Conclusion}

Use of research by dental care

professionals can:

- Ensure that evidence based care is provided

- Improve patient care and treatment

- Assist in the provision of cost effective care

- Improve the working environment for the dental team

- Ensure the right care is given by the right DCP at the right time.

1. Higgs J, Titchen A. Knowledge and reasoning. In Higgs J, Jones M (eds). Clinical reasoning in health professions, $2^{\text {nd }}$ ed. pp 23-32. Oxford: ButterworthHeinemann, 2000.

2. Cowan D. Research issues in health and social care. Cumbria: M\&K Publishing, 2009.

3. Evidence-Based Medicine Working Group. Evidence-based health care: a new approach to teaching the practice of health care. J Dent Educ 1994; 58: 648-653.

4. Richards D, Clarkson J. Evidence-based dentistry: managing information for better practice. London: Quintessence Publishing, 2008.

5. LoBiondo-Wood G, Haber J. Nursing research: methods and critical appraisal for evidence-based practice. London: Mosby/Elsevier, 2010.

6. Holmes S. Systematic search offers a sound evidence base. Nursing Times 1996; 92: 37-39.

7. Parahoo K. Nursing research, principles, process and issues. Hampshire: Palgrave Macmillan, 1997.

8. National Institute for Health and Clinical Excellence. Principles of best practice in clinical audit. London: NICE, 2002.

9. Department of Health. Working for patients. London: The Stationery Office, 1989.

10. Johnson R P, Quinn B F A. The role of clinical audit in general dental practice. Dental Nursing 2011; 7: 32-36.

We are considering holding our own DCP research competition in 2013 in Vital with an exciting prize. This would involve the submission of an audit abstract that had a positive impact on patient care, treatment or experience. If this is something you would be interested in taking part in, please email the Editor, Kate Maynard, to express your interest viaemail on k.maynard@nature.com.

\section{VITAL READER PANEL}

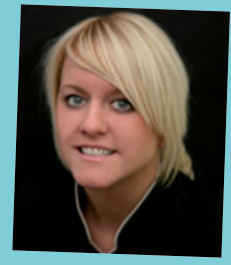

Christine

Horbury,

(Dental Nurse)

Clinical Skills

Educator

'While studying

at the University of Kent I completed a dissertation model titled Does tooth whitening cause sensitivity? A comparison of hydrogen peroxide, and carbamide peroxide. This project question was developed myself and performed by literature review and saw me analysing ten papers. From this critical analysis of ten papers taken from PubMed and Cochrane, I was able to discover why patients possibly had sensitivity and more importantly, as a practice, how we could change practice to benefit our patients. This project made me more critical about what I read and hear. Now working at the University of Leeds, I'm supervising students with literature searching and the use of the CASP tool (critical appraisal skills program). As I now understand research, I'm able to educate others on the importance of evidence based practice.'

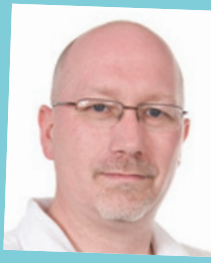

Shaun Howe, Dental Hygienist

'I've never done research as I do not have the best attention span!

That said, I do think we really need to see more DCPs involved in research. For example, infection control. I find it very puzzling as someone who occasionally works alone (without nursing support) that I have to carry out my own infection control yet all the research in how we carry this out has been done by dentists! Would it not be nice to have some DNs carrying out the research and becoming 'experts' in infection control (like their general nursing colleagues) and then providing advice to the Department of Health and not being dictated to by dentists who rarely (if ever) have to carry out infection control? guidelines and protocols, helps to minimis error or harm to patients and can assist in reducing incidents, complaints and/or claims. 